
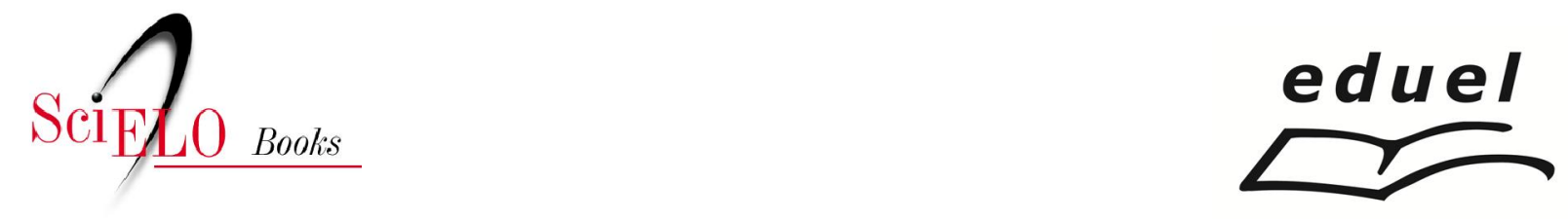

\title{
Adesão ao tratamento da dependência à nicotina
}

\author{
Sandra Odebrecht Vargas Nunes \\ David Roberto do Carmo \\ Heber Odebrecht Vargas \\ Márcia Regina Pizzo de Castro \\ Maria Madalena Batista de Souza Lanssoni \\ Regina Célia Rezende Machado
}

\section{SciELO Books / SciELO Livros / SciELO Libros}

NUNES, SOV., et al. Adesão ao tratamento da dependência à nicotina. In NUNES, SOV., and CASTRO, MRP., orgs. Tabagismo: Abordagem, prevenção e tratamento [online]. Londrina: EDUEL, 2011. pp. 133-181. ISBN 978-85-7216-675-1. Available from SciELO Books

$<\underline{\text { http://books.scielo.org }>\text {. }}$

\section{(1) $(1)(0)$}

All the contents of this work, except where otherwise noted, is licensed under a Creative Commons Attribution-Non Commercial-ShareAlike 3.0 Unported.

Todo o conteúdo deste trabalho, exceto quando houver ressalva, é publicado sob a licença Creative Commons Atribuição Uso Não Comercial - Partilha nos Mesmos Termos 3.0 Não adaptada.

Todo el contenido de esta obra, excepto donde se indique lo contrario, está bajo licencia de la licencia Creative Commons Reconocimento-NoComercial-CompartirIgual 3.0 Unported. 


\title{
Adesão ao tratamento da dependência à nicotina
}

\author{
Sandra Odebrecht Vargas Nunes \\ David Roberto do Carmo \\ Heber Odebrecht Vargas \\ Márcia Regina Pizzo de Castro \\ Maria Madalena Batista de Souza Lanssoni \\ Regina Célia Rezende Machado
}

\section{ABORDAGEM PARA ADESÃO AO TRATAMENTO EM DEPENDENTES DE NICOTINA}

O presente capítulo enfocará uma avaliação das características clínicas e de adesão ao tratamento do tabagismo nos indivíduos que buscaram assistência no Centro de Referência de Abordagem e Tratamento do Tabagismo (CRATT), localizado no Ambulatório do Hospital de Clínicas (AHC) da Universidade Estadual de Londrina, que atende pelo Sistema Único de Saúde (SUS), credenciado pelo Ministério da Saúde, de acordo com a Portaria SAS/MS 442/04. (BRASIL, 2004).

As pessoas que procuram o CRATT, inicialmente, realizam uma abordagem diagnóstica para serem encaminhadas para o programa de cessação do tabagismo. A avaliação clínica inicial identifica as características sociodemográficas, história tabagística, gravidade de dependência da nicotina, comorbidades, idade de início, escala de triagem do uso de álcool, tabaco e outras substâncias, Escala de Depressão de Hamilton e medidas antropométricas.

A dinâmica de tratamento do CRATT consiste em atendimento individual realizado pela psiquiatria e de grupo terapêutico por toda equipe. São realizadas quatro sessões semanais durante o primeiro mês, quinzenais no segundo mês e mensais, até completar um ano. Realiza-se em todas as sessões a verificação do monóxido de carbono, que é considerado o padrão ouro para verificar se o paciente cessou ou não o consumo de tabaco. 
A verificação da adesão ao tratamento dos tabagistas é realizada com 3 meses, 6 meses, 9 meses e 1 ano. Nesse momento, buscam-se informações por meio de um formulário sobre se cessou ou não o consumo de tabaco. Em caso de não ter logrado êxito, são verificados os motivos das recaídas, as barreiras encontradas, a frequência nos grupos terapêuticos, o uso correto da medicação prescrita e como está sua qualidade de vida.

O tabagismo é a maior causa prevenível de morte nos países desenvolvidos. A prevalência do tabagismo entre indivíduos com transtorno mental é de 50\% nos pacientes psiquiátricos, em contraste com os $25 \%$ da população geral. Também 50\% da população geral consegue parar de fumar, enquanto somente $15 \%$ dos pacientes psiquiátricos o fazem. A dependência da nicotina pode ser considerada como uma expressão de vulnerabilidade psicopatológica individual, e isso deve ser ponderado nas intervenções para cessação do consumo de tabaco. (LEMOS, 2006).

Portanto, os profissionais de saúde que atuam nos Ambulatórios de Abordagem e Tratamento do Tabagismo podem utilizar do instrumento de adesão para avaliar a eficácia do tratamento e melhorar as estratégias de intervenção para cessação do uso do cigarro.

Cerca de $80 \%$ dos fumantes querem parar de fumar. No entanto, apenas $3 \%$ conseguem, a cada ano, e a maioria desse grupo consegue parar sem ajuda. A abordagem e o tratamento do fumante chegam a aumentar as taxas de cessação de fumar de $3 \%$ para $20 \%$ a 30\%, em um ano. (BRASIL, 2001).

Dependentes de nicotina têm maior probabilidade de sofrer de transtornos psiquiátricos concomitantes do que a população geral. Cerca de $60 \%$ a $95 \%$ dos indivíduos apresentam dependência de nicotina concomitante com outras substâncias psicoativas, e o tratamento delas, junto com o tabaco, é um desafio. O tratamento de transtornos psiquiátricos coexistentes inclui intervenções psicossociais e/ou farmacológicas. A não adesão pode ter muitos fatores, incluindo comprometimento cognitivo, medo do paciente de 
interações medicamentosas prescritas e as substâncias de abuso, medo que a própria medicação prescrita seja prejudicial, mudança na motivação e falta de apoio. (AMERICAN PSYCHIATRIC ASSOCIATION, 2008).

Mesmo os pacientes que iniciam tratamento com grande motivação para alcançar abstinência terão de lutar contra o reaparecimento da fissura. Além disso, influências sociais (familiares ou amigos), influências econômicas (desemprego), condições de saúde (dores crônicas, fadiga), influências psicológicas (falta de esperança, desespero) aumentam a vulnerabilidade a um episódio de recaída, mesmo quando o indivíduo adere ao tratamento prescrito. $\mathrm{O}$ reconhecimento explícito dos seus esforços e êxitos ajuda a motiválos a permanecer no tratamento, a despeito dos reveses. Pode-se aperfeiçoar seu envolvimento e sua permanência no tratamento utilizando-se estratégias de aumento da motivação e incentivando-os a participar ativamente das estratégias de autoajuda. (AMERICAN PSYCHIATRIC ASSOCIATION. 2008).

Outros obstáculos para a cessação do tabagismo são o medo de ganhar peso, medo da fissura e do fracasso. Os profissionais da saúde, diante do medo do paciente de não conseguir vencer os obstáculos para a cessação do tabagismo e o sentimento de incapacidade de mudar, deve esclarecer sobre esses sentimentos, explorar os motivos pelos quais ele fuma e oferecer apoio e respeito. Quando o paciente tem amigos que fumam ou moram com pessoas que fumam, esses fatores podem representar um obstáculo ao seu tratamento. Deve-se avaliar como essas pessoas favoreceram ou minaram as tentativas anteriores de abandono do cigarro. (AMERICAN PSYCHIATRIC ASSOCIATION, 2008).

\section{MOTIVOS DA NÃO ADESÃO AO TRATAMENTO}

Os seguintes pontos devem ser comunicados aos pacientes tabagistas: 1) a maioria dos fumantes tenta parar de fumar várias vezes antes de finalmente conseguir mas, com persistência, a 
metade de todos os fumantes param; 2) a maioria dos fumantes fracassa nas primeiras tentativas, mas quando é capaz de manter a abstinência por três meses, a recaída é improvável; 3) podese aliviar a abstinência de nicotina com terapia de reposição de nicotina; os verdadeiros sintomas de abstinência, em geral, duram quatro semanas ou mais, e podem incluir disforia ou depressão, irritabilidade, frustração ou raiva, ansiedade, dificuldade de concentração, inquietação, diminuição da frequência cardíaca, aumento do apetite e ganho de peso. (AMERICAN PSYCHIATRIC ASSOCIATION, 2008).

Para manter a adesão ao tratamento, é importante lidar com as suas preocupações sobre o ganho de peso. Os benefícios de parar de fumar para a saúde sem dúvida superam os riscos de aumento de peso. Em média, os fumantes pesam de 2 a 3 quilos menos do que pessoas que nunca fumaram.

O uso de álcool é um fator de risco na maioria dos estudos de recaída no tabagismo; assim é recomendável que os pacientes em tentativa de parar de fumar se abstenham de álcool ou diminuam seu consumo. (AMERICAN PSYCHIATRIC ASSOCIATION, 2008).

Parar de fumar reduz a morbidade e a mortalidade do tabagista. O grau de melhora depende do processo da doença envolvida e a quantidade de dano produzida no tempo da cessação. Por exemplo, fumantes reduzem o risco de desenvolver doença coronariana em 50\% um ano após deixar de fumar. Após quatro anos, o risco torna-se equivalente ao das pessoas que nunca fumaram. Dadas as medidas de custo e efetividade, os profissionais da saúde da atenção primária, além de aconselhar, devem acompanhar o paciente e avaliar a motivação de cessar o tabaco. A avaliação motivacional é usada para medir os processos de mudanças nos cinco estágios: pré-contemplação (não pensa em abandonar o cigarro nos próximos seis meses); contemplação (pensa em abandonar nos próximos seis meses), preparação (pensa em cessar o cigarro nos próximos 30 dias), ação (abandonou o cigarro há menos de seis meses) e manutenção (cessou o cigarro há mais de seis meses). (OKUYEMI; NOLLEN; AHLUWALIA, 2006). 
Nas intervenções terapêuticas para cessação do tabagismo, devem-se avaliar as situações de maior risco de recaídas. Os pacientes que recaem devem ser reforçados a reconsiderar uma nova data para outra tentativa de cessação, pois parar o consumo do tabaco significa reduzir morbidade e mortalidade.

INSTRUMENTO PARA AVALIAÇÃO E ACOMPANHAMENTO DA DEPENDÊNCIA DO TABACO DO CENTRO DE REFERÊNCIA DO AMBULATÓRIO DO HOSPITAL DE CLÍNICAS DA UNIVERSIDADE ESTADUAL DE LONDRINA

A avaliação e o acompanhamento necessitam de instrumentos contendo dados sobre: as características individuais, o grau de dependência de nicotina, a concentração de monóxido de carbono, a motivação para abandonar o tratamento, a capacidade de trabalho e para atividades domésticas, os condicionamentos relacionados ao tabagismo, a história familial para o tabagismo, os tratamentos efetuados anteriores, além de história de outras comorbidades médicas, triagem de substâncias psicoativas e transtorno de humor .

A qualidade de vida (QV) foi avaliada por meio da utilização do WHOQOL-BREF, adaptado e validado para a língua portuguesa por Fleck et al. (2000). Trata-se de um instrumento com 26 questões distribuídas em quatro domínios: saúde física (7 questões), saúde psicológica (6 questões), relações sociais (3 questões), meio ambiente (8 questões) e 2 questões relacionadas com a avaliação global da QV. As propriedades psicométricas do WHOQOL-BREF foram testadas e são adequadas, bem como sua capacidade para avaliar a QV em fumantes. (CASTRO et al., 2007).

O Teste de Triagem do Envolvimento com Álcool, Tabaco e Outras Substâncias (ASSIST versão 3.0) trata-se de um questionário para rastreamento de pessoas que fazem uso de substâncias psicoativas, que abrangem: tabaco, álcool, canabinoides, cocaína, estimulantes do tipo anfetamina, sedativos, alucinógenos, inalantes, opioides e outras drogas. (HENRIQUE et al., 2004, WORLD HEALTH ORGANIZATION, 2002, 2003). 
Os escores para o álcool foram: 0-10 para baixo risco; 1126 para risco moderado e $>27$ para alto risco. A pontuação para todas as outras substâncias foi: 0-3 para baixo risco; 4-26 para risco moderado e $>27$ para alto risco.

Para este estudo, foi adotado o critério de que o participante com pontuação de 27 ou mais, para qualquer substância psicoativa, sugere que é de alto risco de dependência e que possivelmente está com problemas socioeconômicos, de saúde e legais, como resultado de seu abuso.

Os critérios diagnósticos para pesquisa de transtorno de humor e esquizofrenia estarão de acordo com a Décima Revisão da Classificação Internacional de Doenças e Problemas de Saúde Relacionados (CID-10). (ORGANIZAÇÃO MUNDIAL DE SAÚDE, 1998).

Os critérios diagnósticos do transtorno depressivo foram realizados de acordo com a Classificação de Transtornos Mentais e de Comportamento da Classificação Internacional de Doenças (CID-10) para pesquisa. (ORGANIZAÇÃO MUNDIAL DE SAÚDE, 1998). Esses critérios gerais para episódio depressivo são:

A) o episódio depressivo deve durar pelo menos duas semanas, sem episódios maníacos e desordens relacionadas às substâncias.

B) o critério de depressão para os sintomas leve, moderado e grave foi a persistência dos seguintes sintomas:

1) humor deprimido anormal pelo sujeito, na maior parte do dia, quase todos os dias;

2) acentuadamente menor interesse ou prazer em tudo, ou quase tudo, na maior parte das atividades do dia;

3) fadiga ou perda de energia quase todos os dias.

C) os sintomas adicionais são:

1) perda da autoestima e confiança;

2) sentimentos de autorrecriminação ou inutilidade, ou culpa excessiva ou inadequada; 
3) pensamentos recorrentes de morte, ideação suicida ou qualquer comportamento suicida;

4) capacidade de pensar ou concentrar-se diminuída, ou indecisão;

5) alteração na atividade psicomotora com agitação ou lenhificação;

6) qualquer tipo de perturbação do sono;

7) alteração no apetite (diminuição ou aumento), com correspondente alteração de peso.

O episódio depressivo leve deve ter o critério A, dois sintomas do critério B e dois sintomas do critério C. O episódio depressivo moderado deve ter o critério $\mathbf{A}$, dois sintomas do critério $\mathbf{B}$ e quatro sintomas do critério C. O episódio depressivo grave deve ter o critério A, três sintomas do critério B e cinco sintomas do critério $\mathbf{C}$, sem sintomas psicóticos.

O Teste de Fagerström para Dependência de Nicotina (FTND) foi utilizado para avaliar a gravidade da dependência de nicotina, e foi traduzido e adaptado para o português por Carmo e Pueyo (2002). Consta de seis questões, e o escore máximo do teste é 10. Escore maior do que quatro indica maior gravidade. (HEATHERTON et al., 1991; POMERLEAU et al., 1994; FARGERSTRÖM et al., 1978; 1996).

\section{REFERÊNCIAS}

AMERICAN PSYCHIATRIC ASSOCIATION. Diretrizes par o tratamento de transtornos Psiquiátricos Compêndio 2006. Porto Alegre: Artmed, 2008.

BRASIL. Ministério da Saúde. Instituto Nacional de Câncer. Abordagem e tratamento do fumante. Rio de Janeiro: INCA, 2001.

. Ministério da Saúde. Secretaria de Atenção à Saúde. Portaria SAS/MS 442/04 de 13 de agosto de 2004. Aprova o Plano de Implantação da Abordagem e Tratamento do Tabagismo no SUS. Brasília, 2004.

CASTRO, M. G. T.; et al. psychometric properties in a sample of smokers. Rev Bras Psiquiatr, [s.l.], v.29, n.3, p.254-7, 2007. 
CARMO, J. T.; PUEYO, A. A. A adaptação ao português do Fagerström Test for Nicotine Dependence (FTND) para avaliar a dependência e tolerância à nicotina em fumantes. Rev Bras Med. [s.1.], v. 59, n.1/2, p.73-80, 2002.

FAGERSTRÖM, Karl O. Measuring degree of physical dependence to tobacco smoking with reference to individualization of treatment. Addictive Behaviors, Oxford, v.3, n.3/4,p.235-241, 1978.

et al. Nicotine dependence versus smoking prevalence: comparisons among countries and categories of smokers. Tobacco Control, London, v.5, n.1, p. 52-56, 1996.

FLECK, Marcelo et al. Aplicação da versão em português do instrumento de avaliação da qualidade de vida Whoqol-Bref. Revista de Saúde Pública, São Paulo, v.34, n.2, p.178-183, 2000.

HEATHERTON T. F. et al. The Fagerström Test For Nicotine Dependence: a revision of the Fagerström Tolerance Questionnaire. Br J Addict, [s.l.], v.86, n.9, p.1119-27, 1991.

HENRIQUE, Iara Ferraz Silva. et al. Validação da Versão do Teste de Triagem do Envolvimento com Álcool, Cigarro e outras Substâncias (ASSIST). Revista da Associação Medica Brasileira, São Paulo, v.50, n.2, p.1-8, 2004.

LEMOS, T. Tabagismo e comorbidades psiquiátricas. In: Gigliotti A., Presman S. Atualização no Tratamento do Tabagismo. Rio de Janeiro: ABP - Saúde, 2006. p.53-70.

OKUYEMI, K.; NOLLEN, N.; AHLUWALIA, J. Interventions to facilitate smoking cessation. Am Fam Physician, [s.1.], v.74, n.2, p.262-71, 2006.

ORGANIZAÇÃO MUNDIAL DA SAÚDE (OMS). Classificação de Transtorno s Mentais e de Comportamento da CID-10: Critérios Diagnósticos para pesquisa. Porto Alegre: Artes Médicas, 1998. p.94-105.

POMERLEAU, Cynthia S. et al. Reliability of the Fagerström Tolerance questionnaire and the Fagerström test for nicotine dependence. Addictive Behaviors, Oxford, v.19, n.1, p.33-39, 1994.

WORLD HEALTH ORGANIZATION. WHO ASSIST Working Group. The Alcohol, Smoking and Substance Involvement Screening Test (ASSIST): development, reliability and feasibility. Addiction, [s.l.], v.97, n.9, p.11831194, 2002.

The ASSIST project - Alcohol, Smoking and Substance Involvement Screening Test - ASSIST Questionnaire Version 3.0 (Portuguese). Working Group: Guidelines for use in primary care. Draft version only v1.1 september, 2003, p. 6. Disponível em: <http://www.who.int/substance_ abuse/activities/assist/en/>. Acesso em: 6 abr. 2007. 
PROGRAMA DE TABAGISMO - AVALIAÇÃO CLÍNICA

Instrumento Número:

Data da primeira avaliação:

Local:

1.UEL

2.Centros de saúde

Cartão SUS $\mathrm{N}^{\circ}$ : Hygia $\mathrm{N}^{\circ}$ :

Coordenador do Grupo:

Vice Coordenador:

\section{População:}

1. Tabagista trat.c/ grupo terapêutico

8. Desistência

2. Tabagista trat.c/ grupo terapêutico+farmacoterapia

9. Controle

3. Tabagista trat.c/ grupo terapêutico+reposição

10. Psicótico nicotínica(TRN)

4. Tabagista trat.c/ grupo terapêutico+farmacoterapia+TRN

11. Bipolar

12. Câncer

5. Grupo terapia+homeopatia

13. Gestante

6. Grupo terapiathomeopatia+reposição nicotínica(TRN)

7. Grupo terapia+homeopatia+TRN+farmacoterapia

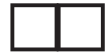

I. Caracterização Sociodemográfica da clientela

Nome/Apelido:

2. Data de Nascimento:

I_-_-_ I

3. Idade (em anos):

4. Naturalidade:

5. Gênero:

1.Masculino

2.Feminino

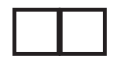

6. Situação conjugal: 1. Solteiro 2.União estável

3.Separado/Divorciado 4.Viúvo

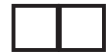
7. Cor da pele: 1.Branca
2.Negra
3.Amarela

4.Mulata

5. Parda

6. Indígena

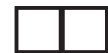


8. Anos de estudo:

9. Nível de Escolaridade:

01. Analfabeto

03. Fundamental incompleto

05.Médio Incompleto

07.Superior Incompleto

09.Pós-graduação latosensu
02. Alfabetizado

04.Fundamental Completo

06. Médio Completo

08.Superior Completo

10.Pós-graduação strictosensu

10. Reside:

1.Sozinho

5.Asilo

2.Parceiro

3.Família

4.Familiares

11. Renda familiar mensal (salários-mínimos):

12. $\mathrm{N}^{\circ}$ dependentes desta renda:

Endereço:

Município: CEP: Estado:

Telefone Contato: Celular: Ramal:

II. Situação de Trabalho 1

13. Local de Trabalho:

Endereço:

Município: CEP: Estado:

14. Formação:

15. Profissão:

16. Ocupação:

17. Relação com o trabalho:

1.Formal 2.Informal

3.Autônomo

4.Servidor Público

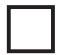

18. Situação trabalhista:

1.Desempregado 2.Auxílio-desemprego

4.Atividade Remunerada 5.Auxílio-doença

7.Aposentado

8.Outro

3.AtividadenãoRemunerada

6.Estudante 
19. Possui doença que o afaste do trabalho:
$1 . \operatorname{sim}$
2.não

$\square$

20. Qual é a doença?

21. Esta doença torna-o incapaz para o trabalho?

$1 . \operatorname{sim}$

2.não

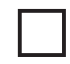

22. No último mês, quantos dias ficou afastado das suas atividades laborais?

23. Qual foi o motivo/doença?

24. No último ano, quantos dias ficou afastado das suas atividades laborais?

25. Qual foi o motivo/doença?

26. Esta doença o incapacitou para as atividades domésticas? $1 . \operatorname{sim}$ 2.não

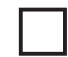

27. Teve alguma internação geral recente:
$1 . \operatorname{sim}$
2.não

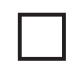

28. Por quantas vezes foi internado?

29. Quantos dias duraram cada internação?

30. Seus colegas de trabalho fumam?
$1 . \operatorname{sim}$
2.não

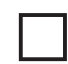

31. Existe no local de trabalho área específica para fumar/fumódromo?

1.sim

2.não

III. dados de encaminhamento

32. A procura deu-se:

1.Voluntariamente

3.Sugestão familiar

5.Sugestão colega de trabalho

2.Por encaminhamento médico ou clínica 4.Sugestão amigo 6.Outro 
IV. abordagem e tratamento do tabagismo

História Pregressa da Doença

33. (01) Você tem ou teve frequentemente aftas, lesões (feridas) e/ou sangramento na boca?

1.Sim

2.Não

33.1. Está em tratamento?

1.Sim

2.Não

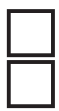

34. (02) Você tem diabetes mellitus?

1.Sim

2.Não

34.1. Está em tratamento?

1.Sim

2.Não

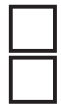

35. (03) Você tem hipertensão arterial?

1.Sim

2.Não

35.1. Está em tratamento?

1.Sim

2.Não

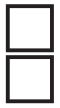

36. (04) Você tem ou teve algum problema cardíaco?

1.Sim 2.Não

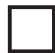

36.1. Qual?

36.2. Está em tratamento?

1.Sim 2.Não

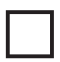

37. (05) Você tem ou teve frequentemente queimação, azia, dor no estômago, úlcera ou gastrite?

1.Sim

2.Não

37.1. Está em tratamento?

1.Sim 2.Não

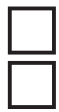

38. (06) Você tem ou teve algum problema pulmonar?

1.Sim 2.Não

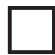

38.1. Qual?

38.2. Está em tratamento?

1.Sim 2.Não

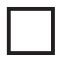

39. (07) Você tem alergia respiratória?

1.Sim

2.Não

39.1. Está em tratamento?

1.Sim

2.Não

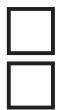

40. (08) Você tem alergia cutânea?
1.Sim
2.Não
40.1. Está em tratamento?
1.Sim 2.Não

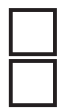


41. (09) Você tem ou teve alguma lesão ou tumor maligno?

1.Sim 2.Não

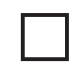

41.1. Onde (local)?

41.2. Está em tratamento?

1.Sim 2.Não

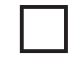

42. (10) Você tem ou teve crise convulsiva, convulsão febril na infância ou epilepsia?
1.Sim
2.Não

42.1. Está em tratamento?

1.Sim 2.Não

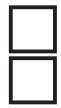

43. (11) Você tem anorexia nervosa ou bulimia?

1.Sim

2.Não

43.1. Está em tratamento?

1.Sim 2.Não

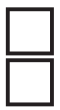

44. (12) Você costuma ter crises de depressão ou ansiedade?

1.Sim 2.Não

44.1. Está em tratamento?

1.Sim 2.Não

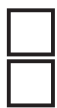

45. (13) Você faz ou fez algum tratamento psicológico ou psiquiátrico?

1.Sim

2.Não

45.1. Está em tratamento?

1.Sim 2.Não

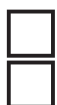

45.2. Qual a medicação?

45.3. Você já tentou suicídio?

1.Sim 2.Não

45.4 Quantas vezes?

45.5 Métodos de tentativa de suicídio
1. Ingestão de medicamento
6. Gás
2. Ingestão de organofosforado
7. Precipitar-se de alturas
3. Enforcamento
8. Precipitar-se de carro em movimento
4. Arma branca
5. Arma de fogo
9. Outros

Caso tenha respondido SIM para as duas questões anteriores (44 e 45), fazer as perguntas sobre Depressão - da 46 à 51; se NẪO, vá direto para a questão 50.

46. (a) Já fez uso de alguma medicação, mesmo que não prescrita por médico, para dormir ou se acalmar?

1.Sim

2.Não

46.1. Qual? 
47. (b1) No último mês você sentiu ou apresentou algum destes sintomas, com duração $>15$ dias: (Assinale com $x$ as alternativas)

Tristeza

Perda de interesse e prazer

Energia reduzida e cansaço

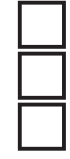

48. (b2) Você sentiu ou apresentou, no último mês, algum destes sintomas por mais de $\mathbf{1 5}$ dias de duração? (Assinale com $\mathrm{x}$ as alternativas)

Concentração e atenção reduzidas

sentimento de culpa e inutilidade

Ideias ou atitudes auto-lesivas ou de suicídio

Apetite alterado

Sono alterado

Autoestima e autoconfiança reduzida

Agitação ou lentificação psicomotora

Pessimismo

\section{Grau de Depressão}

0. Sem critérios

1. Depressão leve - dois sintomas da questão 47 e dois da 48. Além disso, o paciente apresenta dificuldade com o trabalho e atividades sociais, mas não interrompe as funções.

2. Depressão moderada - dois sintomas da questão 47 e três da 48 . Além disso, o paciente apresenta dificuldade considerável em continuar com atividades sociais laboráveis ou domésticas.

3. Depressão grave - três sintomas da questão 47 e cinco sintomas da 48 . Critério de dependência moderada, mais angústia ou agitação considerável. Perda da autoestima. Sentimentos de inutilidade ou culpa e suicídio é um perigo marcante.

\section{0. (c) Há história de transtorno afetivo bipolar?}

1.Sim

2.Não

50.1. Tratamento:

50.2. MDQ

50.3. SCID - Transtorno de Humor

0 . Sem alteração de humor

1. Transtorno Bipolar, tipo Maníaco

2. Transtorno Bipolar, tipo Hipomaníaco

3. Transtorno Bipolar, tipo depressivo 

4. Transtorno Bipolar, tipo Misto
5. Transtorno Depressivo Maior, unipolar
6. Transtorno Depressivo Maior, em Remissão
7. Transtorno Distímoco
8. Transtorno de Humor, devido a uma Condição Médica Geral.
9. Transtorno de Humor, Induzido por Substância

51. (d) O paciente apresentou durante a consulta (Assinale com $x$ as alternativas)
Agitação
Falta de concentração
Pensamento e fala lentificados ou acelerados
Nenhuma alteração

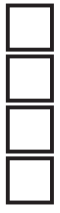

52. (14) Você costuma ingerir bebidas alcoólicas com que frequência?
1.Nunca
2.Todos os dias
3.Finais de semana
4.Raramente

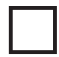

53. (a) Alguma vez você sentiu que deveria diminuir a quantidade de bebida ou parar de beber?

1.Sim 2.Não

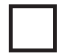

54. (b) As pessoas o aborrecem porque criticam o seu modo de beber?
1.Sim
2.Não

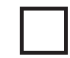

55. (c) Você se sente culpado ou chateado consigo mesmo pela maneira como costuma beber?

1.Sim 2.Não

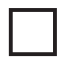

56. (d) Você costuma beber pela manhã para diminuir o nervosismo ou a ressaca?

1.Sim 2.Não

56.1. Três ou quatro questões positivas no CAGE mostram uma tendência importante para o alcoolismo.

1.Sim 2.Não

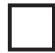

57. (15) Você tem ou teve algum outro problema sério de saúde que não foi citado?

1.Sim

2.Não

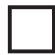

57.1. Qual? 
57.2. Está em tratamento?

57.3. Qual?

58. (16) Algum medicamento em uso atual?

1.Sim 2.Não

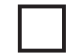

58.1. Qual?

59. (17) Têm prótese dentária móvel?

1.Sim

2.Não

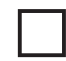

As perguntas 60 e 61 deverão ser respondidas por todos os pacientes do sexo feminino. Se NÃO, ir para a questão 62.

60. (18) Está grávida?

1.Sim

2.Não

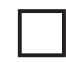

60.1. Quantos meses?

60.2. Número gestações

61. (19) Está amamentando?

1.Sim

2.Não

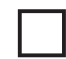

História Tabagistica

62. (01) Com quantos anos você começou a fumar ?

62.1 Quantos anos fuma:

62.2 Quantos cigarros fuma por dia?

62.3 Anos/Maço. (nºcigarros x anos fumando/20)

63. (02) Em quais das situações o cigarro está associado a seu diaa-dia? (Assinale com um $X$ as alternativas que caracterizem esta situação)

Ao falar ao telefone

Com café

Após as refeições

Com bebidas alcoólicas

No trabalho

Ansiedade

Tristeza

Alegria

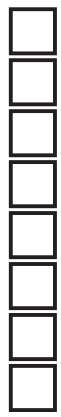


Nenhum

Outros

64. (03) Indique de acordo com algoritmo abaixo qual das afirmativas abaixo você considera, que sejam razões para você fumar?
1.Sim
2. Não
3. Às Vezes

Fumar é um grande prazer

Fumar é muito saboroso

Cigarro me acalma

Acho charmoso fumar

Fumo pra emagrecer

Gosto de fumar para ter alguma coisa nas mãos

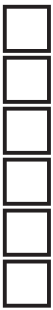

Outros

65. (04) Quantas vezes você tentou parar de fumar?

1.De 1 a 3 vezes

2.Mais de 3 vezes

3.Nunca tentou (seguir para a questão 69)

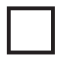

66. (05) Quantas vezes você ficou sem fumar por pelo menos um dia?
1.Uma vez
2.Duas vezes
4.Mais de três vezes
5.Nenhuma vez
3.Três vezes

67. (06) Quais foram os motivos que levaram você a voltar a fumar? (Múltipla escolha)

Bebida

Briga-Raiva

Tensão

Influência

Medo de ganhar peso

Sem motivo aparente

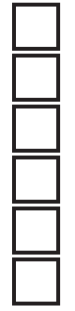

Estressor de perda

Festa

Alegria

Condicionamento

Ansiedade

Outro

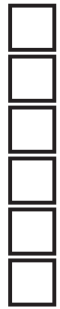

68. (07) Alguma vez na vida utilizou algum recurso para deixar de fumar?

1.Nenhum revistas, jornais e outros

2.Apoio de profissional de saúde

4.1. Qual?

5. Outros
3.Leitura em folhetos, 4.Medicamento 
69. (08) Você participou de algum grupo de apoio para abordagem e tratamento do tabagismo em algum lugar?

1.Sim 2.Não

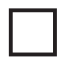

70. Fez uso de tratamento para parar de fumar (pode escolher várias):

\begin{tabular}{lll} 
Bupropiona & $\square$ & $\begin{array}{l}\text { reposição com adesivo } \\
\text { goma }\end{array}$ \\
homeopatia & $\begin{array}{l}\text { grupo terapêutico } \\
\text { apoio aos profissionais de saúde }\end{array}$ \\
\hline$\square$ & outros medicamentos
\end{tabular}

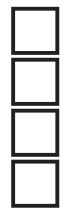
qual?

71. A última vez que ficou abstinente foi por quanto tempo? (em meses)

72. (09) Por que você quer deixar de fumar agora? (Pode assinalar várias alternativas)

Porque está afetando minha saúde

Outras pessoas estão me pressionando

Pelo bem-estar de minha família

Estou preocupado com minha saúde no futuro

Porque meus filhos pedem

Porque não gosto de ser dependente

Fumar é antissocial

Porque gasto muito dinheiro com cigarro

Fumar é um mal exemplo para as crianças

Por conta das restrições de fumar em ambientes fechados

Outros

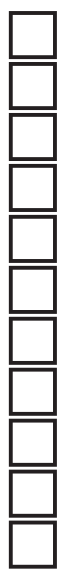

73. (10) Você convive com fumantes na sua casa?

1.Sim 2.Não

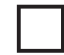

73.1.Qual o grau de parentesco?

74. (11) Você se preocupa em ganhar peso ao deixar de fumar? 1.Sim 2.Não

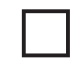


Escala de Tolerância de Fagerstrõm - Gravidade ì DependênCIa de NICOTINA

75. (01) Quanto tempo depois de acordar fuma o primeiro cigarro?
0. Após 60 minutos
2.Entre 06 a 30 minutos
1.Entre 31 a 60 minutos
3.Nos primeiros 5 minutos

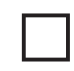

76. (02) Você acha difícil não fumar em lugares onde é proibido, como em igrejas, bibliotecas, local de trabalho, shoppings, etc?

1.Sim $\quad$ Não

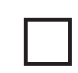

77. (03) Qual o cigarro do dia traz mais satisfação?
1.0 primeiro da manhã
0.Outros

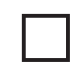

78. (04) Quantos cigarros você fuma por dia?
0. Menos de 10
1. De 11 a 20
2. De $21 \mathrm{a} 30$
3. Mais de 31

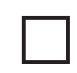

79. (05) Você fuma mais pela manhã?
1.Sim
0.Não

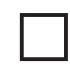

80. (06) Você fuma mesmo doente quando precisa ficar na cama a maior parte do tempo?
1.Sim
0. Não

Pontuação

História Familiar de Tabagismo em Primeiro Grau

81. Seu pai fuma ou já fumou?
1.Sim
2.Não

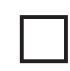

82. Sua mãe fuma ou já fumou?
1.Sim
2.Não

83. Número de irmãos?

84. Quantos deles fumam?

85. Número de filhos?

86. Quantos deles fumam?

87. História familial:
1.Positiva
2.Negativa
3.Desconhecida

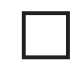


88. História familiar de transtorno mental:

1.Sim 2.Não

88.1.Qual familiar?

88.2.Qual transtorno mental?

Avaliação do Grau de Motivação

89. Grau de Motivação

1. Contemplativo - motivado a parar, porém sem data estipulada nos próximos dias

2. Ação - já tem data marcada ou está motivado a parar dentro de um mês

3. Recaído - retornou ao consumo habitual de cigarros

Exame Físico - Fase 0

90. Altura do paciente (m):

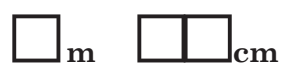

91. Peso (k):
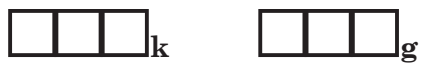

92. IMC - Índice de Massa Corpórea (peso/ altura²):

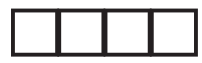

93. PA:

94. FC:

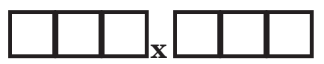

95. Circunferência Abdominal:

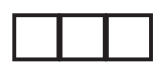

95.2 Circunferência Quadril:

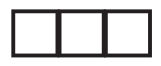

95.3 Teste de Bioimpedância

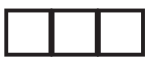

96. ACV:

1.Normal

2.Ritmo regular

3.Ritmo Irregular

96a. Se AVC = Ritmo irregular, Extras Sístoles/minuto: $1 .<5$

$2 .>=5$

97. AR:

1.Normal

2.Roncos e sibilos

3.Diminuição do murmúrio vesicular

98. RXT:

1.Normal

2.DPOC 3.Outros

99. CO exal:

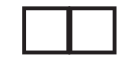


100. Glicemia:

101. Há quanto tempo fumou o último cigarro (horas)?

102. Colesterol

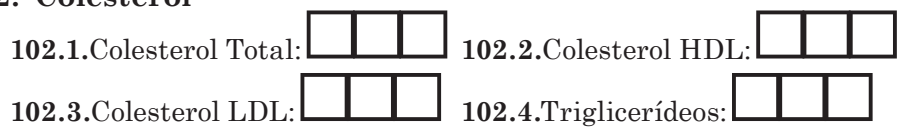

Observações:

103. ASSIST (01) Na sua vida qual dessas substâncias você já usou (Somente uso não médico)

\begin{tabular}{|c|c|c|}
\hline & Não & Sim \\
\hline $\begin{array}{l}\text { 103.1. Derivados do tabaco (cigarro, charuto, cachimbo, fumo de } \\
\text { corda ...) }\end{array}$ & 0 & 3 \\
\hline $\begin{array}{l}\text { 103.2. Bebidas alcoólicas (cerveja, vinho, destilados - pinga, } \\
\text { uísque ...) }\end{array}$ & 0 & 3 \\
\hline 103.3. Maconha (baseado, erva, haxixe ...) & 0 & 3 \\
\hline 103.4. Cocaína, crack (pó, pedra, branquinha, nuvem ...) & 0 & 3 \\
\hline $\begin{array}{l}\text { 103.5. Estimulantes como anfetaminas ou ecstasy ( bolinhas, } \\
\text { rebites ...) }\end{array}$ & 0 & 3 \\
\hline $\begin{array}{l}\text { 103.6. Inalantes (cola de sapateiro, cheirinho-da-loló, tinta, } \\
\text { gasolina, éter ...) }\end{array}$ & 0 & 3 \\
\hline $\begin{array}{l}\text { 103.7. Hipnóticos e sedativos (remédios para dormir, diazepan, } \\
\text { lorax ...) }\end{array}$ & 0 & 3 \\
\hline $\begin{array}{l}\text { 103.8. Drogas Alucinógenas (como LSD, ácido, chá-de-lírio, } \\
\text { cogumelos...) }\end{array}$ & 0 & 3 \\
\hline 103.9. Opióides (heroína, morfina, metadona, coldeína ...) & 0 & 3 \\
\hline 103.10. Outros, Especificar : & 0 & 3 \\
\hline
\end{tabular}

Se NÃO em todos os itens questionar "Nem mesmo quando você estava na escola?".

Se NÃO em todos os itens, pare a entrevista e vá para a questão 111.

Se SIM para alguma droga, prossiga para a questão 104 para cada droga usada. 
104. (02) Durante os três últimos meses, com que frequência você utilizou essa(s) substância(s) que mencionou?

\begin{tabular}{|c|c|c|c|c|c|}
\hline & Nunca & 1 a 2 vezes & $\begin{array}{c}\text { Mensal- } \\
\text { mente }\end{array}$ & $\begin{array}{c}\text { Semanal- } \\
\text { mente }\end{array}$ & $\begin{array}{c}\text { Diaria- } \\
\text { mente } \\
\text { ou quase } \\
\text { todo dia }\end{array}$ \\
\hline $\begin{array}{l}\text { 104.1. Derivados do tabaco (cigarro, } \\
\text { charuto, cachimbo, fumo de corda } \\
\text {...) }\end{array}$ & 0 & 2 & 3 & 4 & 6 \\
\hline $\begin{array}{l}\text { 104.2. Bebidas alcoólicas (cerveja, } \\
\text { vinho, destilados - pinga, uísque ...) }\end{array}$ & 0 & 2 & 3 & 4 & 6 \\
\hline $\begin{array}{l}\text { 104.3. Maconha (baseado, erva, } \\
\text { haxixe ...) }\end{array}$ & 0 & 2 & 3 & 4 & 6 \\
\hline $\begin{array}{l}\text { 104.4. Cocaína, crack (pó, pedra, } \\
\text { branquinha, nuvem ...) }\end{array}$ & 0 & 2 & 3 & 4 & 6 \\
\hline $\begin{array}{l}\text { 104.5. Estimulantes como } \\
\text { anfetaminas ou ecstasy ( bolinhas, } \\
\text { rebites ...) }\end{array}$ & 0 & 2 & 3 & 4 & 6 \\
\hline $\begin{array}{l}\text { 104.6. Inalantes (cola de sapateiro, } \\
\text { cheirinho-da-loló, tinta, gasolina, } \\
\text { éter ...) }\end{array}$ & 0 & 2 & 3 & 4 & 6 \\
\hline $\begin{array}{l}\text { 104.7. Hipnóticos e sedativos } \\
\text { (remédios para dormir, diazepan, } \\
\text { lorax ...) }\end{array}$ & 0 & 2 & 3 & 4 & 6 \\
\hline $\begin{array}{l}\text { 104.8. Drogas Alucinógenas } \\
\text { (como LSD, ácido, chá-de-lírio, } \\
\text { cogumelos...) }\end{array}$ & 0 & 2 & 3 & 4 & 6 \\
\hline $\begin{array}{l}\text { 104.9. Opióides (heroína, morfina, } \\
\text { metadona, coldeína ...) }\end{array}$ & 0 & 2 & 3 & 4 & 6 \\
\hline 104.10. Outras, Especifica & 0 & 2 & 3 & 4 & 6 \\
\hline
\end{tabular}

Se NUNCA em todos os itens da Questão 104, vá para a questão 111.

Se SIM para alguns destes itens prossiga respondendo as questões 105 a 110.

105. (03) Durante os três últimos meses, com que frequência você teve um forte desejo ou urgência em consumir? (Primeira droga, depois a segunda droga, etc).

\begin{tabular}{|c|c|c|c|c|c|}
\hline & Nunca & $\begin{array}{l}1 \text { a } 2 \\
\text { vezes }\end{array}$ & $\begin{array}{l}\text { Mensal- } \\
\text { mente }\end{array}$ & $\begin{array}{c}\text { Semanal- } \\
\text { mente }\end{array}$ & $\begin{array}{c}\text { Diariamen- } \\
\text { te ou quase } \\
\text { todo dia }\end{array}$ \\
\hline $\begin{array}{l}\text { 105.1. Derivados do tabaco (cigarro, } \\
\text { charuto, cachimbo, fumo de corda ...) }\end{array}$ & 0 & 3 & 4 & 5 & 6 \\
\hline $\begin{array}{l}\text { 105.2. Bebidas alcoólicas (cerveja, vinho, } \\
\text { destilados - pinga, uísque ...) }\end{array}$ & 0 & 3 & 4 & 5 & 6 \\
\hline
\end{tabular}




\begin{tabular}{llllll}
\hline 105.3. Maconha (baseado, erva, haxixe ...) & 0 & 3 & 4 & 5 & 6 \\
\hline $\begin{array}{l}\text { 105.4. Cocaína, crack (pó, pedra, } \\
\text { branquinha, nuvem ...) }\end{array}$ & 0 & 3 & 4 & 5 & 6 \\
$\begin{array}{l}\text { 105.5. Estimulantes como anfetaminas ou } \\
\text { ecstasy ( bolinhas, rebites ...) }\end{array}$ & 0 & 3 & 4 & 5 & 6 \\
$\begin{array}{l}\text { 105.6. Inalantes (cola de sapateiro, } \\
\text { cheirinho-da-loló, tinta, gasolina, éter ...) }\end{array}$ & 0 & 3 & 4 & 5 & 6 \\
\hline $\begin{array}{l}\text { 105.7. Hipnóticos e sedativos (remédios } \\
\text { para dormir, diazepan, lorax ...) }\end{array}$ & 0 & 3 & 4 & 5 & 6 \\
$\begin{array}{l}\text { 105.8. Drogas Alucinógenas (como LSD, } \\
\text { ácido, chá-de-lírio, cogumelos...) }\end{array}$ & 0 & 3 & 4 & 5 & 6 \\
\hline $\begin{array}{l}\text { 105.9. Opióides (heroína, morfina, } \\
\text { metadona, coldeína ...) }\end{array}$ & 0 & 3 & 4 & 5 & 6 \\
\hline \begin{tabular}{l} 
105.10. Outras, Especifica \\
\hline
\end{tabular} & 0 & 3 & 4 & 5 & 6
\end{tabular}

106. (04) Durante os últimos três meses com que frequência o seu consumo de (Primeira droga, depois a segunda droga, etc). resultou em problemas de saúde, social, legal ou financeiro?

\begin{tabular}{l|c|c|c|c|c} 
& Nunca & $\begin{array}{c}1 \text { a } 2 \\
\text { vezes }\end{array}$ & $\begin{array}{c}\text { Mensal- } \\
\text { mente }\end{array}$ & $\begin{array}{c}\text { Semanal- } \\
\text { mente }\end{array}$ & $\begin{array}{c}\text { Diariamente } \\
\text { ou quase } \\
\text { todo dia }\end{array}$ \\
\hline $\begin{array}{l}\text { 106.1. Derivados do tabaco (cigarro, } \\
\text { charuto, cachimbo, fumo de corda ...) }\end{array}$ & 0 & 4 & 5 & 6 & 7 \\
\hline $\begin{array}{l}\text { 106.2. Bebidas alcoólicas (cerveja, vinho, } \\
\text { destilados - pinga, uísque ...) }\end{array}$ & 0 & 4 & 5 & 6 & 7 \\
\hline $\begin{array}{l}\text { 106.3. Maconha (baseado, erva, haxixe } \\
\text {..) }\end{array}$ & 0 & 4 & 5 & 6 & 7 \\
\hline $\begin{array}{l}\text { 106.4. Cocaína, crack (pó, pedra, } \\
\text { branquinha, nuvem ...) }\end{array}$ & 0 & 4 & 5 & 6 & 7 \\
\hline $\begin{array}{l}\text { 106.5. Estimulantes como anfetaminas } \\
\text { ou ecstasy (bolinhas, rebites ...) }\end{array}$ & 0 & 4 & 5 & 6 & 7 \\
\hline $\begin{array}{l}\text { 106.6. Inalantes (cola de sapateiro, } \\
\text { cheirinho-da-loló, tinta, gasolina, éter ...) }\end{array}$ & 0 & 4 & 5 & 6 & 7 \\
\hline $\begin{array}{l}\text { 106.7. Hipnóticos e sedativos (remédios } \\
\text { para dormir, diazepan, lorax ...) }\end{array}$ & 0 & 4 & 5 & 6 & 7 \\
\hline $\begin{array}{l}\text { 106.8. Drogas Alucinógenas (como LSD, } \\
\text { ácido, chá-de-lírio, cogumelos...) }\end{array}$ & 0 & 4 & 5 & 6 & 7 \\
\hline $\begin{array}{l}\text { 106.9. Opióides (heroína, morfina, } \\
\text { metadona, coldeína ...) }\end{array}$ & 0 & 4 & 5 & 6 & 7 \\
\hline \begin{tabular}{l} 
106.10. Outras, Especifica \\
\hline
\end{tabular}
\end{tabular}


107. (05) (Durante os três últimos meses, com que frequência por causa do seu uso você deixou de (Primeira droga, depois a segunda droga,etc) você deixou de fazer coisas que eram normalmente esperadas por você?

\begin{tabular}{|c|c|c|c|c|c|}
\hline & Nunca & $\begin{array}{c}1 \text { a } 2 \\
\text { vezes }\end{array}$ & $\begin{array}{c}\text { Mensal- } \\
\text { mente }\end{array}$ & $\begin{array}{c}\text { Semanal- } \\
\text { mente }\end{array}$ & $\begin{array}{c}\text { Diariamen- } \\
\text { te ou quase } \\
\text { todo dia }\end{array}$ \\
\hline $\begin{array}{l}\text { 107.1. Derivados do tabaco (cigarro, charuto, } \\
\text { cachimbo, fumo de corda ...) }\end{array}$ & 0 & 5 & 6 & 7 & 8 \\
\hline $\begin{array}{l}\text { 107.2. Bebidas alcoólicas (cerveja, vinho, } \\
\text { destilados - pinga, uísque ...) }\end{array}$ & 0 & 5 & 6 & 7 & 8 \\
\hline 107.3. Maconha (baseado, erva, haxixe ...) & 0 & 5 & 6 & 7 & 8 \\
\hline $\begin{array}{l}\text { 107.4. Cocaína, crack (pó, pedra, branquinha, } \\
\text { nuvem ...) }\end{array}$ & 0 & 5 & 6 & 7 & 8 \\
\hline $\begin{array}{l}\text { 107.5. Estimulantes como anfetaminas ou } \\
\text { ecstasy (bolinhas, rebites ...) }\end{array}$ & 0 & 5 & 6 & 7 & 8 \\
\hline $\begin{array}{l}\text { 107.6. Inalantes (cola de sapateiro, cheirinho- } \\
\text { da-loló, tinta, gasolina, éter ...) }\end{array}$ & 0 & 5 & 6 & 7 & 8 \\
\hline $\begin{array}{l}\text { 107.7. Hipnóticos e sedativos (remédios para } \\
\text { dormir, diazepan, lorax ...) }\end{array}$ & 0 & 5 & 6 & 7 & 8 \\
\hline $\begin{array}{l}\text { 107.8. Drogas Alucinógenas (como LSD, ácido, } \\
\text { chá-de-lírio, cogumelos...) }\end{array}$ & 0 & 5 & 6 & 7 & 8 \\
\hline $\begin{array}{l}\text { 107.9. Opióides (heroína, morfina, metadona, } \\
\text { coldeína ...) }\end{array}$ & 0 & 5 & 6 & 7 & 8 \\
\hline 107.10. Outras, Especifica & 0 & 5 & 6 & 7 & 8 \\
\hline
\end{tabular}

108. (06) Há amigos, parentes ou outras pessoas que tenha demonstrado preocupação com seu uso de (Primeira Droga, depois a segunda droga, etc.)?

\begin{tabular}{l|c|c|c} 
& $\begin{array}{c}\text { NÃo, } \\
\text { Nunca }\end{array}$ & $\begin{array}{c}\text { SIM, mas não } \\
\text { nos últimos 3 } \\
\text { meses }\end{array}$ & $\begin{array}{c}\text { SIM, nos } \\
\text { útimos 3 } \\
\text { meses }\end{array}$ \\
\hline $\begin{array}{l}\text { 108.1. Derivados do tabaco (cigarro, charuto, } \\
\text { cachimbo, fumo de corda ...) }\end{array}$ & 0 & 3 & 6 \\
\hline $\begin{array}{l}\text { 108.2. Bebidas alcoólicas (cerveja, vinho, destilados } \\
\text { - pinga, uísque ...) }\end{array}$ & 0 & 3 & 6 \\
\hline $\begin{array}{l}\text { 108.3. Maconha (baseado, erva, haxixe ...) } \\
\begin{array}{l}\text { 108.4. Cocaína, crack (pó, pedra, branquinha, } \\
\text { nuvem ...) }\end{array}\end{array} \quad 0 \quad 0$ & 3 & 6 \\
\hline $\begin{array}{l}\text { 108.5. Estimulantes como anfetaminas ou ecstasy } \\
\text { (bolinhas, rebites ...) }\end{array}$ & 0 & 3 & 6 \\
\hline
\end{tabular}


108.6. Inalantes (cola de sapateiro, cheirinho-da-

loló, tinta, gasolina, éter ...)

$\begin{array}{lll}0 & 3 & 6\end{array}$

108.7. Hipnóticos e sedativos (remédios para dormir, diazepan, lorax ...)

$0 \quad 3$

$3 \quad 6$

108.8. Drogas Alucinógenas (como LSD, ácido, chá-

de-lírio, cogumelos...)

108.9. Opióides (heroína, morfina, metadona, coldeína ...)

108.10. Outras, Especifica

$0 \quad 3$

$3 \quad 6$

$0 \quad 3 \quad 6$

$\begin{array}{lll}0 & 6\end{array}$

109. (07) Alguma vez você já tentou controlar, diminuir ou parar o uso de (Primeira droga, depois a segunda droga, etc.)?

\begin{tabular}{|c|c|c|c|}
\hline & $\begin{array}{l}\text { NÃO, } \\
\text { Nunca }\end{array}$ & $\begin{array}{l}\text { SIM, mas não } \\
\text { nos últimos } 3 \\
\text { meses }\end{array}$ & $\begin{array}{l}\text { SIM, nos } \\
\text { últimos } 3 \\
\text { meses }\end{array}$ \\
\hline $\begin{array}{l}\text { 109.1. Derivados do tabaco (cigarro, charuto, } \\
\text { cachimbo, fumo de corda ...) }\end{array}$ & 0 & 3 & 6 \\
\hline $\begin{array}{l}\text { 109.2. Bebidas alcoólicas (cerveja, vinho, destilados } \\
\text { - pinga, uísque ...) }\end{array}$ & 0 & 3 & 6 \\
\hline 109.3. Maconha (baseado, erva, haxixe ...) & 0 & 3 & 6 \\
\hline $\begin{array}{l}\text { 109.4. Cocaína, crack (pó, pedra, branquinha, } \\
\text { nuvem ...) }\end{array}$ & 0 & 3 & 6 \\
\hline $\begin{array}{l}\text { 109.5. Estimulantes como anfetaminas ou ecstasy } \\
\text { (bolinhas, rebites ...) }\end{array}$ & 0 & 3 & 6 \\
\hline $\begin{array}{l}\text { 109.6. Inalantes (cola de sapateiro, cheirinho-da- } \\
\text { loló, tinta, gasolina, éter ...) }\end{array}$ & 0 & 3 & 6 \\
\hline $\begin{array}{l}\text { 109.7. Hipnóticos e sedativos (remédios para dormir, } \\
\text { diazepan, lorax ...) }\end{array}$ & 0 & 3 & 6 \\
\hline $\begin{array}{l}\text { 109.8. Drogas Alucinógenas (como LSD, ácido, chá- } \\
\text { de-lírio, cogumelos...) }\end{array}$ & 0 & 3 & 6 \\
\hline $\begin{array}{l}\text { 109.9. Opióides (heroína, morfina, metadona, } \\
\text { coldeína ...) }\end{array}$ & 0 & 3 & 6 \\
\hline 109.10. Outras, Especifica & 0 & 3 & 6 \\
\hline
\end{tabular}

110. (08) Alguma vez você já usou drogas por injeção? (Apenas uso não médico) 0.Não, nunca
2.Sim, nos últimos 3 meses 
110.1 Pontuação - Hamilton

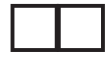

110.2 Pontuação - Tabaco

$$
\text { 1.0-3 2.4-26 } 3.27 \text { ou mais }
$$

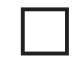

110.3 Pontuação - Bebidas alcoólicas

$$
\text { 1.0-10 2.11-26 } 3.27 \text { ou mais }
$$

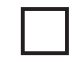

110.4 Pontuação - Maconha

$$
\text { 1.0-3 2.4-26 } 3.27 \text { ou mais }
$$

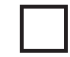

110.5 Pontuação - Cocaína, crack

$$
\text { 1.0-3 2.4-26 } 3.27 \text { ou mais }
$$

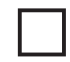

110.6 Pontuação - Estimulantes como anfetaminas ou ecstasy

$$
\text { 1.0-3 } \quad 2.4-26 \quad 3.27 \text { ou mais }
$$

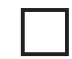

110.7 Pontuação - Inalantes

$$
\text { 1.0-3 2.4-26 } 3.27 \text { ou mais }
$$

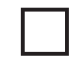

110.8 Pontuação - Hipnóticos e sedativos

$$
\text { 1.0-3 2.4-26 } 3.27 \text { ou mais }
$$

110.9 Pontuação - Drogas alucinógenas

$$
\text { 1.0-3 2.4-26 } 3.27 \text { ou mais }
$$

110.10 Pontuação - Opióides

$$
\text { 1.0-3 2.4-26 } 3.27 \text { ou mais }
$$

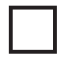

110.11 Pontuação - Outras

$$
\text { 1.0-3 2.4-26 } 3.27 \text { ou mais }
$$


Qualidade de Vida - Escala do WHOQOL - Bref

As perguntas abaixo deverão ser respondidas tendo como referência às duas últimas semanas.

Analise a questão e circule o número que lhe pareça a melhor resposta.

\begin{tabular}{|c|c|c|c|c|c|}
\hline & $\begin{array}{l}\text { Muito } \\
\text { Ruim }\end{array}$ & Ruim & $\begin{array}{l}\text { Nem ruim } \\
\text { Nem boa }\end{array}$ & Boa & Muito Boa \\
\hline \multirow[t]{2}{*}{$\begin{array}{l}\text { 111. (01) Como você avaliaria sua } \\
\text { qualidade de vida? }\end{array}$} & 1 & 2 & 3 & 4 & 5 \\
\hline & \begin{tabular}{|} 
Muito \\
Insatis- \\
feito
\end{tabular} & $\begin{array}{l}\text { Insatis- } \\
\text { feito }\end{array}$ & $\begin{array}{c}\text { Nem satis- } \\
\text { feito, nem } \\
\text { insatis- } \\
\text { feito }\end{array}$ & $\begin{array}{l}\text { Satis- } \\
\text { feito }\end{array}$ & $\begin{array}{c}\text { Muito } \\
\text { Satisfeito }\end{array}$ \\
\hline
\end{tabular}

112. (02) Quão satisfeito você está com sua saúde?

$\begin{array}{lllll}1 & 2 & 3 & 4 & 5\end{array}$

As questões seguintes são sobre o quanto você tem sentido algumas coisas nas últimas duas semanas.

\begin{tabular}{l|l|l|l|l|c|c|c} 
Muito & Mais ou & Bas- & $\begin{array}{c}\text { Extre- } \\
\text { ma- } \\
\text { mente }\end{array}$ \\
\hline
\end{tabular}

113. (03) Em que medida você acha que sua dor (física) impede você de fazer o que você $\begin{array}{llllllll}1 & 2 & 3 & 4 & 5\end{array}$ precisa?

114. (04) O quanto você precisa de algum $\begin{array}{llllllll}\text { tratamento médico para levar sua vida } & 1 & 2 & 3 & 4 & 5\end{array}$ diária?

115. (05) $\mathrm{O}$ quanto você aproveita a vida? $\quad 1 \quad 2 \quad \begin{array}{lllll} & 3 & 4 & 5\end{array}$

116. (06) Em que medida você acha que sua $\begin{array}{lllllll}1 & 2 & 3 & 4 & 5\end{array}$
vida tem sentido?

117. (07) O quanto você consegue se concentrar?

$\begin{array}{lllll}1 & 2 & 3 & 4 & 5\end{array}$

118. (08) Quão seguro(a) você se sente com a vida diária?

$\begin{array}{lllll}1 & 2 & 3 & 4 & 5\end{array}$

119. (09) Quão saudável é o seu ambiente físico (clima, barulho, poluição, atrativos)? 
As questões seguintes perguntam sobre quão completamente você tem sentido ou é capaz de fazer certas coisas nestas últimas duas semanas

\begin{tabular}{l|c|c|c|c|c} 
& Nada & $\begin{array}{c}\text { Muito } \\
\text { Pouco }\end{array}$ & Médio & Muito & $\begin{array}{c}\text { Completa- } \\
\text { mente }\end{array}$ \\
\hline $\begin{array}{l}\text { 120. (10) Você tem energia suficiente } \\
\text { para o seu dia-a-dia? }\end{array}$ & 1 & 2 & 3 & 4 & 5 \\
\hline
\end{tabular}

$\begin{aligned} & \text { 121. (11) Você é capaz de aceitar a sua } \\ & \text { aparência física? }\end{aligned}$
$\begin{aligned} & \text { 122. (12) Você tem dinheiro suficiente } \\ & \text { para satisfazer suas necessidades? }\end{aligned}$

123. (13) Quão disponíveis para você $\begin{array}{llllllll}\text { estão as informações que precisa para } & 1 & 2 & 3 & 4 & 5\end{array}$ seu dia-a-dia?

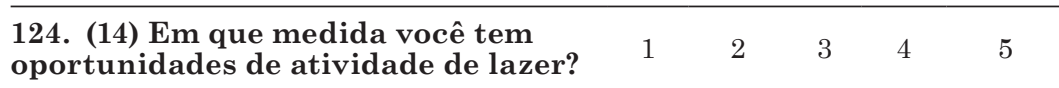

As questões seguintes perguntam sobre quão bem ou satisfeito você se sentiu a respeito de vários aspectos de sua vida nas últimas duas semanas.

\begin{tabular}{l|c|c|c|c|c} 
& $\begin{array}{c}\text { Muito } \\
\text { Ruim }\end{array}$ & Ruim $\mid \begin{array}{c}\text { Nem ruim } \\
\text { Nem bom }\end{array}$ & Bom & $\begin{array}{c}\text { Muito } \\
\text { Bom }\end{array}$ \\
\hline $\begin{array}{l}\text { 125. (15) Quão bem você é capaz de se } \\
\text { locomover? }\end{array}$ & 1 & 2 & 3 & 4 & 5
\end{tabular}
locomover?

\begin{tabular}{c|c|c|c|c} 
Muito & Nem satis- \\
$\begin{array}{c}\text { Insatis- } \\
\text { feito }\end{array}$ & $\begin{array}{c}\text { Insatis- } \\
\text { feito }\end{array}$ & $\begin{array}{c}\text { feito Nem } \\
\text { insatis- } \\
\text { feito }\end{array}$ & Satisfeito & Muito \\
Satisfeito
\end{tabular}

126. (16) Quão satisfeito(a) você está com seu sono?

$\begin{array}{lllll}1 & 2 & 3 & 4 & 5\end{array}$

127. (17) Quão satisfeito(a) você está com a sua capacidade de desempenhar as atividades do seu dia-a-dia?

128. (18) Quão satisfeito(a) você $\begin{array}{llllllll}\text { está com sua capacidade de } & 1 & 2 & 3 & 4\end{array}$ trabalho?

129. (19) Quão satisfeito(a) você está consigo mesmo?

$\begin{array}{lllll}1 & 2 & 3 & 4 & 5\end{array}$

130. (20) Quão satisfeito(a) você está com suas relações pessoais (amigos, parentes, conhecidos,

$\begin{array}{lllll}1 & 2 & 3 & 4 & 5\end{array}$
colegas)? 
131. (21) Quão satisfeito(a) você está com sua vida sexual?

132. (22) Quão satisfeito(a) você está com o apoio que você recebe de seus amigos?

133. (23) Quão satisfeito(a) você está com as condições do local onde mora?

134. (24) Quão satisfeito(a) você está com seu acesso aos serviços de saúde?

135. (25) Quão satisfeito(a) você está com seu meio de transporte?

1

1

$\begin{array}{llll}2 & 3 & 4 & 5\end{array}$

$\begin{array}{llllllll} & 1 & 2 & 3 & 4 & 5\end{array}$

5

$\begin{array}{lllll}1 & 2 & 3 & 4 & 5\end{array}$

$\begin{array}{lllllll}\text { de } & 1 & 2 & 3 & 4 & 5\end{array}$
As questões seguintes referem-se a com que frequência você sentiu ou experimentou
certas coisas nas últimas duas semanas.

\begin{tabular}{c|c|c|c|c|c} 
Nunca & $\begin{array}{c}\text { Algumas } \\
\text { Vezes }\end{array}$ & $\begin{array}{c}\text { Frequente- } \\
\text { mente }\end{array}$ & $\begin{array}{c}\text { Muito } \\
\text { Freqüente- } \\
\text { mente }\end{array}$ & Sempre \\
\hline
\end{tabular}

136. (26) Com que frequencia

você tem sentimentos negativos

tais como mau humor, desespero,

12

$3 \quad 4 \quad 5$

ansiedade, depressão?

Alguém lhe ajudou a preencher este questionário?

Quanto tempo você levou para preencher este questionário?

Você tem algum comentário sobre o questionário?

\section{Sessões Terapêuticas}

\section{Situação Paciente (Sit Pac.)}
1.Fumante
2.Não fumante
4.Lapso recaída
5.Lapso abstinência
3.Não compareceu
3. Não comparec
6. Abandono

\section{Tratamento (Tratam.)}

01.Grupo

03.Grupo+goma

05.Grupo+bupropriona

02.Grupo+adesivo

04.Grupo+adesivo+goma

07Grupo+bupropriona+adesivo+goma

09.Grupo+ISRS

06.Grupo+bupropriona+adesivo

11.Grupo+ISRS+goma

13. Grupo+nortriptilina

08.Grupo+bupropriona+goma

10.Grupo+ISRS+adesivo

12.Grupo+ISRS+goma+adesivo

14. Grupo+nortriptilina+goma

15.Grupo+nortriptilina+adesivo

17.Nenhum

16.Grupo+nortriptilina+adesivo+goma

19.Outro

18.Grupo+outro 
Monóxido de Carbono exalado (CO exal) - PPM e \%

\begin{tabular}{|c|c|c|c|c|c|c|c|}
\hline & Sit.Pac. & Tratam. & $\begin{array}{l}\text { CO exal } \\
\% \quad \text { ppm }\end{array}$ & & Sit.Pac. & Tratam. & $\begin{array}{l}\text { CO exal } \\
\% \quad \text { ppm }\end{array}$ \\
\hline Avaliação & $\square$ & $\square \square$ & $\square \square \square$ & 9Sessão & $\square$ & $\square$ & $\square \square \square$ \\
\hline 1 Sessão & $\square$ & $\square$ & $\square \square \square$ & 10 Sess. & $\square$ & $\square$ & $\square \square \square$ \\
\hline 2 Sessão & $\square$ & $\square \square$ & $\square \square \square$ & 11 Sess. & $\square$ & $\square$ & $\square \square \square$ \\
\hline 3 Sessão & $\square$ & $\square$ & $\square \square \square$ & 12 Sess. & $\square$ & $\square$ & $\square \square \square$ \\
\hline 4 Sessão & $\square$ & $\square$ & $\square \square \square$ & 13 Sess. & $\square$ & $\square$ & $\square \square \square$ \\
\hline 5 Sessão & $\square$ & $\square \square$ & $\square \square \square$ & 14 Sess. & $\square$ & $\square$ & $\square \square \square$ \\
\hline 6 Sessão & $\square$ & $\square$ & $\square \square \square$ & 15 Sess. & $\square$ & $\square$ & $\square \square \square$ \\
\hline 7 Sessão & $\square$ & $\square$ & $\square \square \square$ & 16 Sess. & $\square$ & $\square$ & $\square \square \square$ \\
\hline 3 Sessão & $\square$ & $\square$ & $\square \square \square$ & 17 Sess. & $\square$ & $\square$ & $\square \square \square$ \\
\hline
\end{tabular}

138. Oximetria

Saturação de $\mathrm{O}^{2}$ :

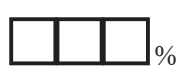

\section{Outros}

139.1 Dosagem IL-6 - Fase 0:

139.2 Dosagem da PCR - Fase 0:

139.3. 5HTT - Polimorfismo - Fase 0:

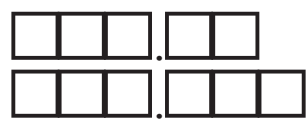

139.4 TNF a - Fase 0:

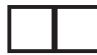

139.5 IL- 1 - Fase 0:

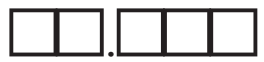

139.6 IL- 4 - Fase 0:

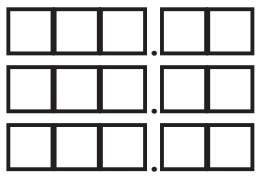

139.7 IL- 10 - Fase 0:

139.8 Potencial Antioxidante Total Plasmático - (TRAP)Fase 0:

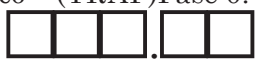

139.9 Dialdeído Malônico (MDA) - Fase 0:

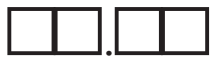

139.10 Óxido Nítrico (medida indireta) - Fase 0:

139.11 Hidroperóxidos Lipídicos (FOX) - Fase 0:

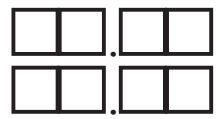

139.12 Produtos Avançados de Proteínas Oxidadas (AOPP) - Fase 0:

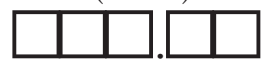


139.13 Hb A1c - Fase 0:

139.14 a 1 glicoproteína ácida - Fase 0:

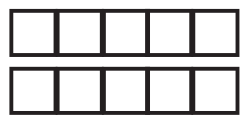

139.15 Insulina - Fase 0:

139.16 Gama GT - Fase 0:

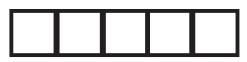

139.17 Ácido úrico - Fase 0:

139.18 Fibrinogênio - Fase 0:

139.19 Homocisteína - Fase 0:

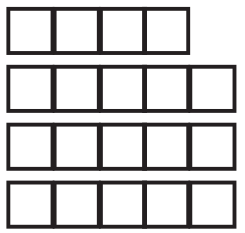

139.20 Função Pulmonar - fase 0:

CVF:

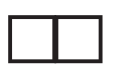

$\mathrm{VEF}_{1}$ :

$\mathrm{IVEF}_{1} / \mathrm{CVF}$ :
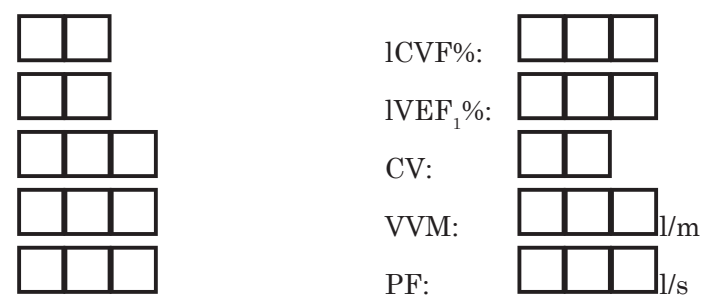

$1 \mathrm{CV} \%$ :

VVM\%:

PF:

139.21 Índice de Capacidade para o Trabalho - Fase 0:

140. Como você descreveria a melhor estimativa de adesão ao tratamento prescrito?

1. Não tomou a medicação durante as últimas 12 semanas

2. Quase sempre é aderente à medicação prescrita

3. Adere ao tratamento cerca da metade do tempo

4. Nunca é aderente ao tratamento prescrito

5. Adere totalmente à medicação prescrita

6. Transtorno de Humor, devido a uma Condição Médica Geral.

7. Transtorno de Humor, Induzido por Substância

141. Indique a razão de sua não aderência ao tratamento prescrito?

1. Não aplicável

2. Falta de eficácia parcial da medicação prescrita 
3. Intolerância ao tratamento prescrito

4. Falta de medicação prescrita na instituição

5. Outro

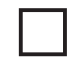

Resultados $\quad 3$ meses

142. Cessação do tabaco:

1.Sim 2.Não

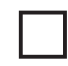

143. Recaída em 3 meses:

1.Sim

2.Não

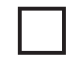

144. Participação na intervenção cognitiva(dias)

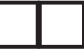

145. Quantos dias após a intervenção abandonou o tabagismo?

146. Barreiras para não abandonar o tabagismo?

1.Sim

2.Não

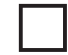

147. Medo de ganhar peso?

1.Sim 2.Não

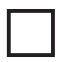

148. Dificuldades com os sintomas de abstinência?

1.Sim

2.Não

Quais?

149. Agravamento dos problemas emocionais?

1.Sim

2.Não

Quais?

150. Sentimentos de perda de controle?

1.Sim 2.Não

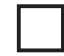

151. Não conseguiu resistir à fissura?

1.Sim

2.Não

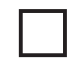

\section{Qualidade de vida}

152. Como você avaliaria sua qualidade de vida?
1.muito ruim
4.boa
2.ruim
5.muito boa
3.nem ruim e nem boa 
153. Quão satisfeito(a) você está com a sua saúde?
1.muito insatisfeito
2.insatisfeito
3.nem satisfeito/nem insatisfeito
4.boa
5.muito satisfeito

As questões seguintes são sobre o quanto você tem sentido algumas coisas nas últimas duas semanas:

154. Em que medida você acha que sua dor(física) impede de fazer o que precisa?
1.nada
4.bastante
2.muito pouco
5.extremamente
3.mais ou menos

155. O quanto você precisa de algum tratamento médico para levar sua vida diária?
1.nada
4.bastante
2.muito pouco
3.mais ou menos
5.extremamente

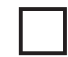

156. O quanto você aproveita a vida?
1.nada
4.bastante
2.muito pouco
5.extremamente
3.mais ou menos

157. Em que medida você acha que sua vida tem sentido?
1.nada
4.bastante
2.muito pouco
5.extremamente
3.mais ou menos

158. Quão seguro(a) você se sente em sua vida diária?
1.nada
4.bastante
2.muito pouco
5.extremamente
3.mais ou menos

159. Quão saudável é o seu ambiente físico (clima, barulho, poluição, atrativos)?
1.nada
4.bastante
2.muito pouco
5.extremamente
3.mais ou menos

As questões seguintes perguntam sobre quão completamente você tem sentido ou é capaz de fazer certas coisas nestas últimas duas semanas:

160. Você tem energia suficiente para seu dia a dia?
1.nada
4.muito
2.muito pouco
3.médio
5.completamente

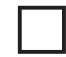

161. Você é capaz de aceitar sua aparência física?
1.nada
4.bastante
2.muito pouco
3.mais ou menos
5.extremamente 
162. Você tem dinheiro suficiente para satisfazer suas necessidades?
1.nada
2.muito pouco
4.bastante
5.extremamente
3.mais ou menos

163. Quão disponíveis para você estão as informações que precisa no seu dia-a-dia?
1.nada
2.muito pouco
3.mais ou menos
4.bastante
5.extremamente

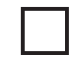

164. Em que medida você tem oportunidades de atividade de lazer?
1.nada
4.bastante
2.muito pouco
3.mais ou menos
5.extremamente

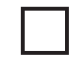

As questões seguintes perguntam sobre quão bem ou satisfeito você se sentiu a respeito de vários aspectos de sua vida nas últimas duas semanas:

165. Quão bem você é capaz de se locomover?
1.muito ruim
4.bom
2.ruim 3.nem ruim nem bom
5.muito bom

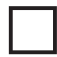

166. Quão satisfeito(a) você está com o seu sono?
1.muito insatisfeito
2.insatisfeito
3.nem satisfeito nem insatisfeito
4.satisfeito

5.muito satisfeito

167. Quão satisfeito(a) você está com sua capacidade de desempenhar as atividades do seu dia a dia?
1.muito insatisfeito
2.insatisfeito
3.nem satisfeito nem insatisfeito
4.satisfeito

5.muito satisfeito

168. Quão satisfeito(a) você está com sua capacidade para o trabalho?
1.muito insatisfeito
2.insatisfeito
3.nem satisfeito nem insatisfeito
4.satisfeito

5.muito satisfeito

169. Quão satisfeito(a) você está consigo mesmo?
1.muito insatisfeito
2.insatisfeito
3.nem satisfeito nem insatisfeito
4.satisfeito
5.muito satisfeito

170. Quão satisfeito(a) você está com suas relações pessoais (amigos, parentes, conhecidos, colegas)
1.muito insatisfeito
2.insatisfeito
3.nem satisfeito nem insatisfeito
4.satisfeito

5.muito satisfeito 
171. Quão satisfeito(a) você está com sua vida sexual?

1.muito insatisfeito

3.nem satisfeito nem insatisfeito

2.insatisfeito

5.muito satisfeito

4.satisfeito

172. Quão satisfeito(a) você está com o apoio que você recebe de seus amigos?
1.muito insatisfeito
3.nem satisfeito nem insatisfeito
2.insatisfeito
5.muito satisfeito
4.satisfeito

173. Quão satisfeito(a) você está com as condições do local onde mora?
1.muito insatisfeito
3.nem satisfeito nem insatisfeito
2.insatisfeito
5.muito satisfeito
4.satisfeito

174. Quão satisfeito(a) você está com o seu acesso aos serviços de saúde?
1.muito insatisfeito
3.nem satisfeito nem insatisfeito
2.insatisfeito
4.satisfeito
5.muito satisfeito

175. Quão satisfeito(a) você está com seu meio de transporte?

1.muito insatisfeito

2.insatisfeito

3.nem satisfeito nem insatisfeito

5.muito satisfeito

4.satisfeito

As questões seguintes referem-se a com que frequência você sentiu ou experimentou certas coisas nas últimas duas semanas.

176. Com que frequência você tem sentimentos negativos tais como mau humor, desespero, ansiedade, depressão?
1.nunca
3.frequentemente
2.algumas vezes
5.sempre
4.muito frequentemente

Alguém lhe ajudou a preencher este questionário?

Quanto tempo você levou para preencher este questionário?

Você tem algum comentário sobre o questionário?

\section{Barreiras:}

1.Cessou

2.Não cessou

177.1 Se não cessou, Barreiras para não abandonar: (múltipla escolha): 
Ansiedade

Pressão social

Estresse no trabalho

Estresse na família

Álcool

Alegria

Não sabe

Prazer

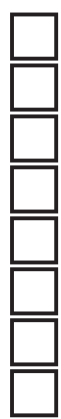

Medo de ganhar peso

Condicionamento café

Solidão

Condicionamento $1^{\circ}$ cigarro

Tristeza

Desibinição

Medo de fissura

Outros

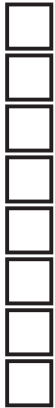

6 MESES

178. Como você descreveria a melhor estimativa de adesão ao tratamento prescrito?

1. Não tomou a medicação durante as últimas 12 semanas

2. Quase sempre é aderente à medicação prescrita

3. Adere ao tratamento cerca da metade do tempo

4. Nunca é aderente ao tratamento prescrito

5. Adere totalmente a medicação prescrita

179. Indique a razão de sua não aderência ao tratamento prescrito?

1. Não aplicável

2. Falta de eficácia parcial da medicação prescrita

3. Intolerância ao tratamento prescrito

4. Falta de medicação prescrita na instituição

\section{Resultados 6 meses}

180. Cessação do tabaco:

1.Sim

2.Não

181. Recaída em 6 meses:

1.Sim

2.Não

182. Participação na intervenção cognitiva(dias) 
183. Quantos dias após a intervenção abandonou o tabagismo?

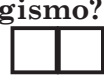

184. Barreiras para não abandonar o tabagismo?

1.Sim 2.Não

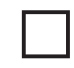

185. Medo de ganhar peso?

1.Sim

2.Não

$\square$

186. Dificuldades com os sintomas de abstinência?

1.Sim

2.Não

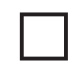

Quais?

187. Agravamento dos problemas emocionais?

1.Sim

2.Não

Quais?

188. Sentimentos de perda de controle?

1.Sim

2.Não

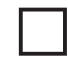

189. Não conseguiu resistir à fissura?

1.Sim

2.Não

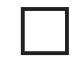

190. Barreiras:

1.Cessou

2.Não cessou

190.1 Se não cessou, Barreiras para não abandonar: (múltipla escolha):

Ansiedade

Pressão social

Estresse no trabalho

Estresse na família

Álcool

Alegria

Não sabe

Prazer

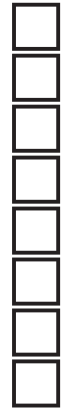

Medo de ganhar peso

Condicionamento café

Solidão

Condicionamento $1^{\circ}$ cigarro

Tristeza

Desibinição

Medo de fissura

Outros

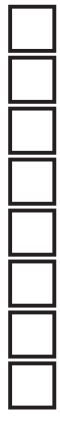


191. Como você descreveria a melhor estimativa de adesão ao tratamento prescrito?

1. Não tomou a medicação durante as últimas 12 semanas

2. Quase sempre é aderente à medicação prescrita

3. Adere ao tratamento cerca da metade do tempo

4. Nunca é aderente ao tratamento prescrito

5. Adere totalmente à medicação prescrita

192. Indique a razão de sua não aderência ao tratamento prescrito?
1. Não aplicável
2. Falta de eficácia parcial da medicação prescrita
3. Intolerância ao tratamento prescrito
4. Falta de medicação prescrita na instituição

\section{Resultados 9 meses}

193. Cessação do tabaco:

1.Sim

2.Não

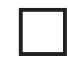

194. Recaída em 9 meses:

1.Sim

2.Não

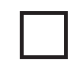

195. Participação na intervenção cognitiva(dias)

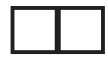

196. Quantos dias após a intervenção abandonou o tabagismo?

197. Barreiras para não abandonar o tabagismo?

1.Sim 2.Não

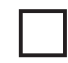

198. Medo de ganhar peso?

1.Sim

2.Não

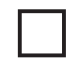

199. Dificuldades com os sintomas de abstinência?
1.Sim
2.Não

Quais? 
200. Agravamento dos problemas emocionais?

1.Sim 2.Não

Quais?

201. Sentimentos de perda de controle?

1.Sim

2.Não

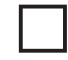

202. Não conseguiu resistir à fissura?

1.Sim 2.Não

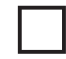

Qualidade de vida

203. Como você avaliaria sua qualidade de vida?
1.muito ruim
4.bom
2.ruim 3.nem ruim nem bom
5.muito bom

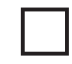

204. Quão satisfeito(a) você está com a sua saúde?
1.muito insatisfeito
3.nem satisfeito nem insatisfeito
2.insatisfeito
4.boa

5.muito satisfeito

As questões seguintes são sobre o quanto você tem sentido algumas coisas nas últimas duas semanas:

205. Em que medida você acha que sua dor(física) impede de fazer o que precisa?
1.nada
4.bastante
2.muito pouco
5.extremamente
3.mais ou menos

206. O quanto você precisa de algum tratamento médico para levar sua vida diária?
1.nada
4.bastante
2.muito pouco
5.extremamente
3.mais ou menos

207. O quanto você aproveita a vida?
1.nada
4.bastante
2.muito pouco
5.extremamente
3.mais ou menos

208. Em que medida você acha que sua vida tem sentido?
1.nada
4.bastante
2.muito pouco
5.extremamente
3.mais ou menos 
209. Quão seguro(a) você se sente em sua vida diária?.
1.nada
4.bastante
2.muito pouco
5.extremamente
3.mais ou menos

210. Quão saudável é o seu ambiente físico (clima, barulho, poluição, atrativos)?
1.nada
4.bastante
2.muito pouco
5.extremamente
3.mais ou menos

As questões seguintes perguntam sobre quão completamente você tem sentido ou é capaz de fazer certas coisas nestas últimas duas semanas:

211. Você tem energia suficiente para seu dia a dia?
1.nada
4.muito
2.muito pouco
5.completamente
3.médio

212. Você é capaz de aceitar sua aparência física?
1.nada
4.muito
2.muito pouco
5.completamente
3.médio

213. Você tem dinheiro suficiente para satisfazer suas necessidades?
1.nada
4.muito
2.muito pouco
5.completamente
3.médio

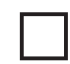

214. Quão disponíveis para você estão as informações que precisa no seu dia a dia?
1.nada
4.muito
2.muito pouco
5.completamente
3.médio

215. Em que medida você tem oportunidades de atividade de lazer?
1.nada
4.muito
2.muito pouco
3.médio
5.completamente

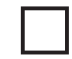

As questões seguintes perguntam sobre quão bem ou satisfeito você se sentiu a respeito de vários aspectos de sua vida nas últimas duas semanas:

216. Quão bem você é capaz de se locomover?
1.muito ruim
3.nem ruim nem bom
2.ruim
5.muito bom
4.bom

217. Quão satisfeito(a) você está com o seu sono?
1.muito insatisfeito
2.insatisfeito
3.nem satisfeito nem insatisfeito
4.satisfeito
5.muito satisfeito 
218. Quão satisfeito(a) você está com sua capacidade de desempenhar as atividades do seu dia a dia?
1.muito insatisfeito
2.insatisfeito
3.nem satisfeito nem insatisfeito
4.satisfeito

5.muito satisfeito

219. Quão satisfeito(a) você está com sua capacidade para o trabalho?
1.muito insatisfeito
3.nem satisfeito nem insatisfeito
5.muito satisfeito

\author{
2.insatisfeito \\ 4.satisfeito
}

220. Quão satisfeito(a) você está consigo mesmo?
1.muito insatisfeito
3.nem satisfeito nem insatisfeito
2.insatisfeito

5.muito satisfeito

4.satisfeito

221. Quão satisfeito(a) você está com suas relações pessoais (amigos, parentes, conhecidos, colegas)
1.muito insatisfeito
3.nem satisfeito nem insatisfeito
2.insatisfeito
5.muito satisfeito
4.satisfeito

222. Quão satisfeito(a) você está com sua vida sexual?
1.muito insatisfeito
3.nem satisfeito nem insatisfeito
2.insatisfeito
4.satisfeito

5.muito satisfeito

223. Quão satisfeito(a) você está com o apoio que você recebe de seus amigos?
1.muito insatisfeito
2.insatisfeito
3.nem satisfeito nem insatisfeito
4.satisfeito
5.muito satisfeito

224. Quão satisfeito(a) você está com as condições do local onde mora?
1.muito insatisfeito
3.nem satisfeito nem insatisfeito
2.insatisfeito
5.muito satisfeito
4.satisfeito

225. Quão satisfeito(a) você está com o seu acesso aos serviços de saúde?
1.muito insatisfeito
3.nem satisfeito nem insatisfeito
2.insatisfeito
5.muito satisfeito
4.satisfeito

226. Quão satisfeito(a) você está com seu meio de transporte?

1.muito insatisfeito

2.insatisfeito

3.nem satisfeito nem insatisfeito

4.satisfeito

5.muito satisfeito 
As questões seguintes referem-se a com que frequência você sentiu ou experimentou certas coisas nas últimas duas semanas.

227. Com que frequência você tem sentimentos negativos tais como mau humor, desespero, ansiedade, depressão?

1.nunca

3.frequentemente

2.algumas vezes

5.sempre

4.muito frequentemente

Alguém lhe ajudou a preencher este questionário?

Quanto tempo você levou para preencher este questionário?

Você tem algum comentário sobre o questionário?

\section{Barreiras:}

1.Cessou

2.Não cessou

190.1 Se não cessou, Barreiras para não abandonar: (múltipla escolha):

Ansiedade

Pressão social

Estresse no trabalho

Estresse na família

Álcool

Alegria

Não sabe

Prazer

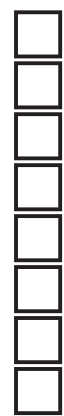

Medo de ganhar peso

Condicionamento café

Solidão

Condicionamento $1^{\circ}$ cigarro

Tristeza

Desibinição

Medo de fissura

Outros

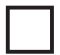


230. Indique a razão de sua não aderência ao tratamento prescrito?

1. Não aplicável

2. Falta de eficácia parcial da medicação prescrita

3. Intolerância ao tratamento prescrito

4. Falta de medicação prescrita na instituição

\section{Resultados $\quad 12$ meses}

231. Cessação do tabaco:

1.Sim 2.Não

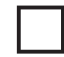

232. Recaída em 1 ano:

1.Sim

2.Não

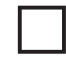

233. Participação na intervenção cognitiva(dias)

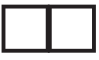

234. Quantos dias após a intervenção abandonou o tabagismo?

235. Barreiras para não abandonar o tabagismo?

1.Sim

2.Não

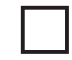

236. Medo de ganhar peso?

1.Sim

2.Não

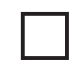

237. Dificuldades com os sintomas de abstinência?

1.Sim

2.Não

Quais?

238. Agravamento dos problemas emocionais?

1.Sim

2.Não

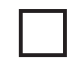

Quais?

239. Sentimentos de perda de controle?
1.Sim
2.Não

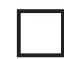

240. Não conseguiu resistir à fissura?
1.Sim
2.Não 


\section{Qualidade de vida}

241. Como você avaliaria sua qualidade de vida?

1.muito ruim

4.boa 2.ruim 3.nem ruim nem boa

5.muito boa

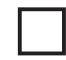

242. 242. Quão satisfeito(a) você está com a sua saúde?

1.muito insatisfeito

3.nem satisfeito nem insatisfeito

5.muito satisfeito 2.insatisfeito

4.boa

As questões seguintes são sobre o quanto você tem sentido algumas coisas nas últimas duas semanas:

243. Em que medida você acha que sua dor(física) impede de fazer o que precisa?
1.nada
2.muito pouco
5.extremamente
3.mais ou menos
4.bastante

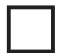

244. . O quanto você precisa de algum tratamento médico para levar sua vida diária?
1.nada
2.muito pouco
3.mais ou menos
4.bastante
5.extremamente

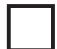

245. O quanto você aproveita a vida?
1.nada
2.muito pouco
4.bastante
5.extremamente
3.mais ou menos

246. Em que medida você acha que sua vida tem sentido?
1.nada
2.muito pouco
3.mais ou menos
4.bastante
5.extremamente

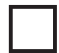

247. Quão seguro(a) você se sente em sua vida diária?
1.nada
4.bastante
2.muito pouco
5.extremamente
3.mais ou menos

248. Quão saudável é o seu ambiente físico (clima, barulho, poluição, atrativos)?
1.nada
4.bastante
2.muito pouco
5.extremamente
3.mais ou menos

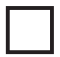

As questões seguintes perguntam sobre quão completamente você tem sentido ou é capaz de fazer certas coisas nestas últimas duas semanas:

249. Você tem energia suficiente para seu dia a dia?
1.nada
4.muito
2.muito pouco
3.médio
5.completamente 
250. Você é capaz de aceitar sua aparência física?
1.nada
2.muito pouco
3.médio
4.muito
5.completamente

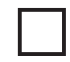

251. Você tem dinheiro suficiente para satisfazer suas necessidades?

1.nada

4.muito

2.muito pouco

5.completamente

3.médio

252. Quão disponíveis para você estão as informações que precisa no seu dia-a-dia?
1.nada
4.muito
2.muito pouco
3.médio
5.completamente

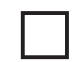

253. Em que medida você tem oportunidades de atividade de lazer?
1.nada
2.muito pouco
5.completamente
3.médio
4.muito

As questões seguintes perguntam sobre quão bem ou satisfeito você se sentiu a respeito de vários aspectos de sua vida nas últimas duas semanas:

254. Quão bem você é capaz de se locomover?
1.muito ruim
4.bom
2.ruim
5.muito bom
3.nem ruim/nem bom

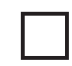

255. Quão satisfeito(a) você está com o seu sono?

1.muito insatisfeito

2.insatisfeito

3.nem satisfeito/nem insatisfeito

4.boa

5.muito satisfeito

256. Quão satisfeito(a) você está com sua capacidade de desempenhar as atividades do seu dia-a-dia?
1.muito insatisfeito
3.nem satisfeito nem insatisfeito
2.insatisfeito
5.muito satisfeito
4.boa

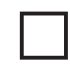

257. Quão satisfeito(a) você está com sua capacidade para o trabalho?
1.muito insatisfeito
3.nem satisfeito nem insatisfeito
2.insatisfeito
5.muito satisfeito
4.boa

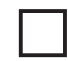

258. Quão satisfeito(a) você está consigo mesmo?

1.muito insatisfeito

3.nem satisfeito nem insatisfeito

2.insatisfeito

5.muito satisfeito

4.boa 
259. Quão satisfeito(a) você está com suas relações pessoais (amigos, parentes, conhecidos, colegas)
1.muito insatisfeito
2.insatisfeito
3.nem satisfeito nem insatisfeito
4.boa
5.muito satisfeito

260. Quão satisfeito(a) você está com sua vida sexual?
1.muito insatisfeito
3.nem satisfeito nem insatisfeito
2.insatisfeito
4.boa

5.muito satisfeito

261. Quão satisfeito(a) você está com o apoio que você recebe de seus amigos?
1.muito insatisfeito
2.insatisfeito
3.nem satisfeito nem insatisfeito
4.boa
5.muito satisfeito

262. Quão satisfeito(a) você está com as condições do local onde mora?
1.muito insatisfeito
3.nem satisfeito nem insatisfeito
2.insatisfeito
5.muito satisfeito
4.boa

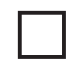

263. Quão satisfeito(a) você está com o seu acesso aos serviços de saúde?
1.muito insatisfeito
3.nem satisfeito nem insatisfeito
2.insatisfeito
5.muito satisfeito
4.boa

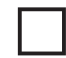

264. Quão satisfeito(a) você está com seu meio de transporte?

1.muito insatisfeito

3.nem satisfeito nem insatisfeito

2.insatisfeito

5.muito satisfeito

4.boa

As questões seguintes referem-se a com que frequência você sentiu ou experimentou certas coisas nas últimas duas semanas.

265. Com que frequência você tem sentimentos negativos tais como mau humor, desespero, ansiedade, depressão?
1.nunca
2.algumas vezes
3.freqüentemente
4.muito frequentemente
5.sempre

Alguém lhe ajudou a preencher este questionário?

Quanto tempo você levou para preencher este questionário?

Você tem algum comentário sobre o questionário?

\section{Barreiras:}

1.Cessou 2.Não cessou 
190.1 Se não cessou; Barreiras para não abandonar: (múltipla escolha):

Ansiedade

Pressão social

Estresse no trabalho

Estresse na família

Álcool

Alegria

Não sabe

Prazer

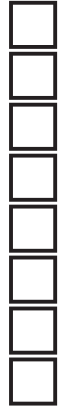

Medo de ganhar peso

Condicionamento café

Solidão

Condicionamento $1^{\circ}$ cigarro

Tristeza

Desibinição

Medo de fissura

Outros

\section{Oximetria}

Saturação de $\mathrm{O}^{2}$

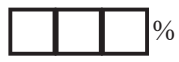

\section{Outros}

268.1 Dosagem IL-6 - Fase 1:

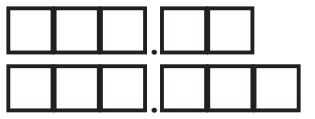

268.2 Dosagem PCR - Fase 1:

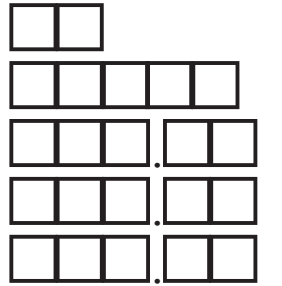

268.3 5 HTT - Polimorfismo - Fase 1:

268.4 TNF a - Fase 1:

268.5 IL- 1 - Fase 1:

268.6 IL- 4 - Fase 1:

268.7 IL- 10 - Fase 1:

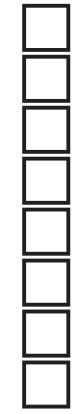

268.8 Potencial Antioxidante Total Plasmático - (TRAP)Fase 1:

268.9 Dialdeído Malônico (MDA) - Fase 1:

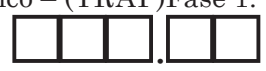

268.10 Óxido Nítrico (medida indireta) - Fase 1:

268.11 Hidroperóxidos Lipídicos (FOX) - Fase 1:

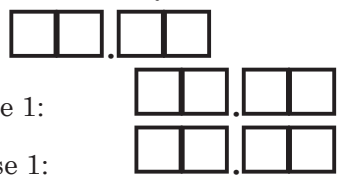

268.12 Produtos Avançados de Proteínas Oxidadas (AOPP) - Fase 1:

268.13 Hb A1c - Fase 1:

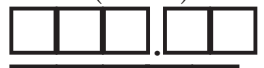

268.14 a1 glicoproteína ácida - Fase 1:

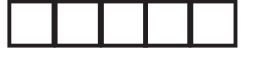

268.15 Insulina - Fase 1:

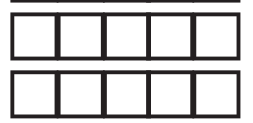


268.16 Gama GT - Fase 1:

268.17 Ácido úrico - Fase 1:

268.18 Fibrinogênio - Fase 1:

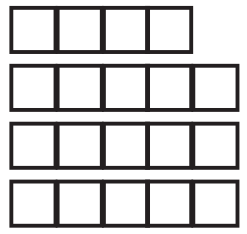

268.19 Homocisteína - Fase 1:

268.20 Função Pulmonar - Fase 1:

CVF:

$\mathrm{VEF}_{1}$ :

$\mathrm{VEF}_{1} / \mathrm{CVF}$ :

CV\%:

VVM\%:

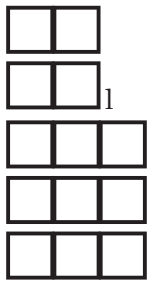

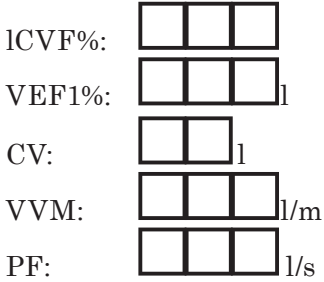

PF:

268.21 Índice de Capacidade para o Trabalho - Fase 1:

\section{Exame Físico- Fase 1:}

1. Altura do paciente:
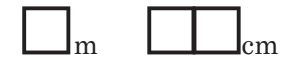

2. Peso:
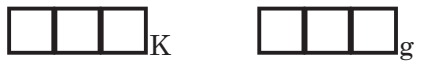

3. IMC - Índice de Massa Corpórea (peso/ altura²):

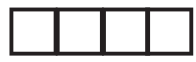

4. PA:

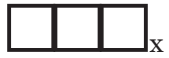

5. FC:

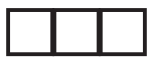

6. AR:

1.Normal

2.Roncos e sibilos

3.Diminuição do murmúrio vesicular
7. RXT:
1.Normal
2.DPOC
3.Outros
8. ACV:
1.Normal
2.Ritmo Regular
3.Ritmo Irregular

8a. Se AVC $=$ Ritmo irregular, Extras Sístoles/minuto:

$1 .<5 \quad 2 .>=5$

9. Circunferência Abdominal:

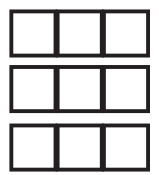

11. Colesterol Total: 
12. Colesterol HDL:

13. Colesterol LDL:

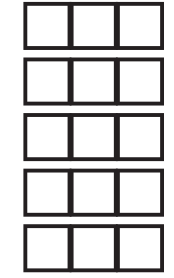

14. Glicemia:

15. Circunferência. Quadril:

16. Teste de Bioimpedância: 
